\title{
Factors associated with preimplantation genetic diagnosis acceptance among women concerned about hereditary breast and ovarian cancer
}

\author{
Susan T. Vadaparampil, PhD ${ }^{1,2}$, Gwendolyn P. Quinn, PhD ${ }^{1,2}$, Caprice Knapp, PhD ${ }^{3}$, \\ Teri L. Malo, $M P H^{1}$, and Susan Friedman, DVM $M^{1,4}$
}

\begin{abstract}
Purpose: To assess sociodemographic, clinical, awareness, and attitudinal factors associated with acceptance of preimplantation genetic diagnosis among women concerned about hereditary breast and ovarian cancer. Methods: Participants $(n=962)$ were members of a national advocacy organization dedicated to empowering women at high risk for developing breast or ovarian cancer. Participants completed a webbased survey assessing factors associated with preimplantation genetic diagnosis acceptance. Factors significantly associated with acceptance in the bivariate analyses were used to build a logistic regression model. Results: Among the 962 respondents, 318 (33.1\%) selected the option that they would consider preimplantation genetic diagnosis, 367 (38.2\%) would not consider preimplantation genetic diagnosis, and 277 $(28.8 \%)$ selected "don't know." Significant predictors of preimplantation genetic diagnosis acceptance were the desire to have more children, having had a prenatal genetic test, preimplantation genetic diagnosis awareness, belief that preimplantation genetic diagnosis is acceptable for individuals at risk for hereditary breast and ovarian cancer, belief that preimplantation genetic diagnosis information should be given to individuals at risk for hereditary breast and ovarian cancer, concerns about preimplantation genetic diagnosis, perceived benefits of preimplantation genetic diagnosis, and how preimplantation genetic diagnosis is considered. Conclusion: Women at increased risk for hereditary cancer may consider preimplantation genetic diagnosis as part of their reproductive decision making. Therefore, it is important to understand existing levels of awareness and attitudes toward this technology to provide optimal counseling and support. Genet Med 2009:11(10):757-765.
\end{abstract}

Key Words: BRCA, PGD, attitudes, awareness, high-risk women

$\mathrm{H}$ ereditary breast and ovarian cancer (HBOC) is associated with deleterious mutations in the $B R C A 1$ or $B R C A 2$ $(B R C A)$ genes that account for approximately $5-10 \%$ of all breast and ovarian cancer cases. ${ }^{1-3} B R C A$ mutations confer an estimated $60-80 \%$ lifetime risk of breast cancer and a $10-54 \%$ lifetime risk of ovarian cancer., ${ }^{4,5}$ In addition to women's personal risks, children of $B R C A$ carriers have a $50 \%$ chance of inheriting the mutation. ${ }^{3}$ The possibility of transmitting a mu-

From the ${ }^{1}$ Health Outcomes and Behavior Program, Division of Population Sciences; Moffitt Cancer Center, Tampa; ${ }^{2}$ Department of Oncologic Science, College of Medicine University of South Florida, Tampa; ${ }^{3}$ Departments of Epidemiology and Health Policy Research and the Institute for Child Health Policy, University of Florida, Gainesville; and ${ }^{4}$ Facing Our Risk of Cancer Empowered (FORCE), Tampa, Florida.

Gwendolyn P. Quinn, PhD, 12902 Magnolia Drive, MRC-CANCONT, Tampa, FL 33612. E-mail: gwen.quinn@moffitt.org.

Disclosure: The authors declare no conflict of interest.

Submitted for publication February 24, 2009.

Accepted for publication June 19, 2009.

Published online ahead of print August 25, 2009.

DOI: $10.1097 /$ GIM.0b013e3181b3f451 tation to a child may pose a concern to families affected by HBOC, ${ }^{6}$ perhaps to the extent that some carriers may avoid childbearing. ${ }^{7-9}$ These concerns also may prompt women to consider using prenatal diagnosis methods to help reduce the risk of transmission. ${ }^{6,10}$ Prenatal diagnosis is an encompassing term used to refer to any medical procedure conducted to assess the presence of a genetic disorder in a fetus. Methods include amniocentesis and chorionic villous sampling (CVS). ${ }^{11,12}$ Both procedures carry some risk of miscarriage, and some evidence suggests fetal defects may result from using these tests. ${ }^{11,12}$ Moreover, discovering the fetus is a carrier for a genetic defect may impose a difficult decision for couples regarding pregnancy continuation or termination.

A viable alternative to these tests is preimplantation genetic diagnosis (PGD), a procedure used to test fertilized eggs for genetic disorders before uterine implantation, ${ }^{6,9,13-15}$ thereby avoiding the potential dangers associated with amniocentesis and CVS and the decision to terminate a pregnancy. ${ }^{16}$ PGD involves the use of in vitro fertilization (IVF) in which eggs are fertilized and the embryos develop for 3 days until it reaches the eight-cell stage; then, one cell from each embryo is removed and examined using polymerase chain reaction or fluorescence in situ hybridization. $6,12,14$ Before the procedure, potential parents can decide whether or not to implant. Originally used for carriers of X-linked diseases (e.g., Fragile X syndrome), PGD use has been expanded to detect single gene defects and chromosomal disorders, such as cystic fibrosis, Huntington disease, and Down syndrome. ${ }^{11,12,14}$ More recently, PGD has been used to detect cancer predisposition, including BRCA mutations. ${ }^{6,17}$ The first case report of an Australian baby born after PGD for a BRCA1 mutation was published in $2008 .{ }^{15}$ In a following report of a case series of 10 women seeking consultation about PGD for a BRCA mutations in Israel, five underwent the procedure, which resulted in three pregnancies with three live births (a set of twins and a singleton; the third pregnancy was ongoing). ${ }^{16}$

Few studies have been conducted to assess high-risk women's interest in PGD. 6,9,10,18 Previous studies have reported conflicting views of PGD as an acceptable option for high-risk individuals. Menon et al., ${ }^{18}$ who surveyed female $B R C A$ gene mutation carriers in the United Kingdom about PGD use, found about $75 \%$ felt offering PGD to individuals who carried a $B R C A$ mutation was acceptable. However, only 15 of the 40 women who completed childbearing reported that they would have considered PGD, and just one of seven considering a future pregnancy would think about using PGD. However, other studies have found higher levels of acceptance toward PGD. Staton et al. ${ }^{6}$ found that although the majority of respondents expressed concern their children would inherit a $B R C A$ mutation, $40 \%$ of women would consider using PGD. Similarly, 57\% of the women studied by Quinn et al. ${ }^{10}$ felt PGD was acceptable for high-risk women and 33\% reported that they would consider using PGD. Most recently, a Spanish study of 77 individuals attending one of four clinics for $B R C A$ testing found $47 \%$ reported that they would consider PGD for $B R C A{ }^{9}$ 
These studies provide important insights into the issues of PGD among women at increased risk for HBOC. However, the small sample sizes have limited the ability to examine the relationship between PGD acceptance and future intention to have children, while simultaneously adjusting for other sociodemographic, clinical, and attitudinal factors. Thus, the purpose of this study was to assess sociodemographic, clinical, awareness, and attitudinal factors associated with acceptance of PGD among women concerned about HBOC.

\section{MATERIALS AND METHODS}

\section{Participant recruitment and data collection}

A waiver of informed consent was obtained through the University of South Florida institutional review board. This study used a cross-sectional web-based survey design. The researchers targeted the members of Facing Our Risk of Cancer Empowered (FORCE), a national advocacy organization dedicated to empowering women whose family history or genetic status puts them at high risk for developing breast or ovarian cancer. This organization has a large online community that regularly posts and seeks information regarding HBOC (www.facingourrisk.org). The survey was limited to individuals visiting the website who: (1) were female and (2) had not participated in a previous study on this topic conducted at the 2007 annual FORCE conference.6,10

The executive director of FORCE emailed all list-serve members a recruitment letter, which included a description of the survey, instructions, the survey password, and a link to the survey website. The letter was signed by the director and the study investigators. If an ineligible participant tried to enter the survey, they were redirected to a message thanking them for their interest and restating their ineligibility. Members were also given the option to contact the study team to complete a hard copy instead of the web survey. One participant chose this option.

The website was available from November 8, 2007, to January 8,2008 . After participants submitted the survey, an email address was provided giving them an opportunity to enter a raffle for one $\$ 50$ gift certificate by emailing their contact information to a study team member. Survey responses could not be linked to raffle participants' contact information. The raffle was held 3 days after the close of the survey, and the gift certificate was mailed to the winner. The remaining respondents' contact information was destroyed after the drawing.

\section{Instrument}

The web-based questionnaire was developed by the investigative team and the executive director of FORCE, and subsequently pilot tested with five FORCE members. This survey was previously administered to 125 high-risk women in a study on this topic conducted among FORCE annual conference attendees. ${ }^{10}$ The survey included five sections assessing sociodemographic, clinical, awareness, attitudinal factors, and acceptance of PGD.

\section{Sociodemographic characteristics}

The following self-reported sociodemographic characteristics were assessed: race/ethnicity (non-Hispanic white or other; race/ ethnicity was assessed given results from previous studies in the genetics of hereditary cancer that suggest knowledge and attitudes may differ by this demographic characteristic) marital status (currently married/living with someone as married or single/never married/separated/divorced/widowed); education ( $<$ high school, completed high school, $\geq$ some college); age $(<41$ or $>41)$; religion (catholic or Christian/Protestant, or Jewish or other); currently have children (yes or no); and wish to have more children (yes or no).

\section{Clinical characteristics}

The following self-reported clinical characteristics were assessed: personal history of breast cancer (yes < age of 50 years, yes $>$ age of 50 years, or no); personal history of ovarian cancer (yes or no); first degree relative with either breast or ovarian cancer (yes or no); carry a $B R C A$ mutation (yes or no); female family member carries a $B R C A$ mutation (yes or no); ever had prenatal genetic test (yes or no, or don't know/never pregnant); and ever used IVF (yes or no).

\section{Awareness of PGD}

Respondents were asked whether they had heard of PGD before the current survey (yes or no).

\section{Attitudes related to $P G D$}

Given the previous literature suggesting low levels of PGD awareness among individuals at increased risk for hereditary cancers, ${ }^{6,10,18}$ respondents were provided with a brief definition of PGD: "Preimplantation Genetic Diagnosis (PGD) is a genetic test performed on embryos produced through in vitro fertilization and used to determine if they are with or without gene mutation. Test results are used to inform prospective parents about the status of the embryos before transfer to a woman's uterus." 19 This definition was followed by a series of attitudinal items. The first set of items assessed whether: (1) PGD was an acceptable option for families with HBOC (yes or no); (2) women with a strong history of breast or ovarian cancer may opt not to have children due to fear of passing on the mutation (yes or no); and (3) individuals with a strong history of breast or ovarian cancer should be provided information about PGD by their healthcare provider (yes or no). The next set of items were adapted from a survey conducted by the Genetics and Public Policy Center on the public's attitudes toward assisted reproductive technology. ${ }^{19,20}$ The first question asked respondents to select their greatest worry related to the use of PGD from a series of options: (1) too much like playing God; (2) too new to be used safely; (3) most people will not be able to afford; (4) can be used for wrong purposes; or (5) don't know or other (asked to write in). The second question asked respondents to select what they perceived to be the greatest benefit of PGD from a series of options: (1) parents can improve chances their baby will be free of genetic mutations; (2) parents can improve chances their child will have features that they want; (3) the overall cost of healthcare will be less; (4) certain genetic diseases will be wiped out forever; or (5) don't know or other (asked to write in). The last question asked whether participants thought about topics such as PGD mainly in terms of: (1) health and safety; (2) religion and morality; (3) both health and safety and religion and morality; or (4) don't know or other (asked to write in).

\section{Acceptance of PGD}

This factor was assessed by asking respondents whether they would ever consider using PGD (yes, no, or not sure).

\section{Data analysis}

All analyses were performed using a standard statistical software package (STATA, version 10.0), and all $P$ values are two sided with a statistical significance level set at $P \leq 0.05$. Analyses comparing individuals who selected the option yes, no, or not sure about use of PGD were carried out using $\chi^{2}$ tests of heterogeneity for categorical variables. A multiple logistic regression model was then built by using variables that demonstrated significant $(P \leq$ $0.05)$ relationships with acceptance of PGD in bivariate analyses. 
The 277 respondents who answered "don't know" to having heard of genetic tests were excluded from the regression analysis.

\section{RESULTS}

Among the 962 respondents, 318 (33.1\%) selected the option that they would consider PGD, 367 (38.2\%) would not consider PGD, and 277 (28.8\%) selected “don't know." PGD acceptance by demographic, clinical, awareness, and attitudinal factors is presented in Table 1. Regarding demographic and clinical characteristics, PGD acceptance was significantly associated with religion $(P<0.001)$, the desire to have more children $(P=0.02)$, and whether the participant had a previous prenatal genetic test $(P<$ $0.001)$. Awareness was significantly associated with PGD acceptance $(P<0.001): 46.9 \%$ of participants who had ever heard of PGD testing said they would consider using it, whereas $29.5 \%$ of participants who had not heard of PGD selected this option.

With respect to attitudinal factors (concerns, benefits, and how PGD is considered), all variables were significantly associated with PGD acceptance $(P<0.001)$. Of the participants who said they would consider using PGD, most agreed that: (1) PGD is an acceptable option for families with a history of HBOC $(88.4 \%)$, (2) women at increased risk for HBOC may choose not to have children due to fear of passing on a hereditary cancer gene (71.4\%), and (3) individuals at increased risk for HBOC should be provided with information about PGD (98.4\%). In contrast, participants who would not consider using PGD tended to disagree with these statements. Those who would consider using PGD were most concerned about affordability (47.2\%), whereas people who would not consider using PGD were most concerned that it was too much like playing God $(36.2 \%)$. Individuals who were unsure about whether they would use PGD were most concerned that it may be used for the wrong purpose $(32.1 \%)$. When asked what they thought was the greatest benefit of PGD, the majority of individuals who would consider PGD or were not sure whether they would consider it, selected the option "the parents can improve the chances their baby will be free of genetic mutations" $(56.9 \%$ and $41.9 \%$, respectively). Most (48.0\%) individuals who would not consider using PGD selected the "other" option. When asked how they considered PGD, the majority of individuals who would consider PGD or were not sure whether they would consider it said that it was mainly a "health and safety issue" $(81.5 \%$ and $44.0 \%$, respectively). The majority $(38.2 \%)$ of participants who would not consider using PGD selected the option that it was a "health and safety issue" and a matter of religion and morality.

\section{Multivariate analysis}

In multivariate analysis, several factors were independently associated with PGD acceptance (Table 2). Of the demographic characteristics, those who did not wish to have children were less likely to accept PGD (odds ratio [OR] $=0.17 ; 95 \%$ confidence interval [CI]: 0.07-0.38), when compared with participants who wished to have children or more children than they currently have. With regard to clinical characteristics, participants who had a prenatal genetic test were more than twice as likely $(\mathrm{OR}=2.45 ; 95 \% \mathrm{CI}: 1.09-5.51)$ to indicate that they would accept PGD relative to participants who did not know whether they had a prenatal genetic test or were never pregnant.

Several awareness and attitudinal factors remained significantly associated with PGD acceptance in the multivariate analysis. Respondents who had not heard of PGD before the survey were about half as likely (OR $=0.51 ; 95 \% \mathrm{CI}: 0.29-0.90)$ to accept PGD, when compared with those who had heard of PGD. PGD acceptance was lower among those who said PGD was not acceptable for those who were at increased risk for HBOC $(\mathrm{OR}=0.29 ; 95 \% \mathrm{CI}: 0.10-0.81)$ or were unsure whether it was acceptable (OR $=0.43$; 95\% CI: $0.24-0.79)$. PGD acceptance also was lower among respondents who were not sure whether PGD information should be given to individuals at risk for HBOC $(\mathrm{OR}=0.16 ; 95 \%$ CI: $0.04-0.57)$ than those who thought information should be provided.

Regarding PGD concerns, those who said that PGD was "too new to be used safely" (OR $=3.01 ; 95 \% \mathrm{CI}$ : 1.01-8.97), unaffordable $(\mathrm{OR}=11.07$; 95\% CI: 4.26-28.77), or that it can be used for the wrong purpose $(\mathrm{OR}=5.59 ; 95 \% \mathrm{CI}=2.25$ 13.90) were more likely to accept PGD, when compared with respondents who said that PGD was "too much like playing God." Concerning perceived benefits of PGD, those who said that parents can improve the chances their baby will be free of genetic mutations $(\mathrm{OR}=3.28 ; 95 \% \mathrm{CI}$ : $1.72-6.23)$ or that certain genetic diseases will be wiped out forever $(\mathrm{OR}=5.12$; 95\% CI: 2.53-10.37) were more likely to accept PGD than those who selected the "other" option. Relative to those who considered PGD mainly in the context health and safety, participants who selected the option that it was mainly religion and morality $(\mathrm{OR}=0.14 ; 95 \% \mathrm{CI}: 0.04-0.48)$, both health and safety and religion and morality $(\mathrm{OR}=0.31 ; 95 \% \mathrm{CI}$ : 0.18 $0.53)$, or other $(\mathrm{OR}=0.19 ; 95 \% \mathrm{CI}: 0.05-0.67)$ were less likely to accept PGD.

\section{DISCUSSION}

In this study, acceptance of PGD was significantly greater among individuals who wished to have more children, previously had prenatal genetic testing, previously heard of PGD, considered it acceptable for others to have PGD, and held views of PGD that were less focused on religious issues.

Previous studies have shown mixed results when examining the relationship between acceptance of PGD and desire for future children. In a study of 284 members of FORCE with $B R C A$ mutations (aged 25-40 years) who participated in an on-line survey about reproductive concerns, only $13 \%$ were likely to consider currently available reproductive strategies, such as PGD, despite the majority expressing a concern about transmitting $B R C A$ mutations to their children. ${ }^{6}$ In subgroup analysis, women without children were more likely to consider assisted reproduction strategies, when compared with those with children. In another study of 77 high-risk individuals from Spain, expressing a favorable attitude toward PGD was not associated with whether an individual already had a child. ${ }^{9}$ Conversely, in a survey of 111 women attending the annual FORCE conference, acceptance of PGD did not differ based on whether respondents had children. ${ }^{10}$ In a study of $52 \mathrm{BRCA}$ mutation carriers from a high-risk clinic in the United Kingdom, ${ }^{18}$ only $14 \%(n=1)$ of women contemplating future pregnancy would personally consider use of PGD, when compared with $38 \%$ who already had children. However, each of these studies had a small number of women who either did not have biological children or wished to have future children. Thus, the responses of a few individuals may have influenced study results substantially.

Another factor associated with acceptance of PGD was previously having had prenatal genetic diagnosis (e.g., amniocentesis or CVS). These procedures have a risk of miscarriage and limited evidence suggests fetal defects may result from using these tests. ${ }^{11,12,21}$ Additionally, detection of disease in a developing fetus places couples in a difficult situation regarding their decision to continue or terminate the pregnancy. Given the age of our study population and the relatively recent clinical avail- 
Table 1 Acceptance of preimplantation genetic diagnosis (PGD) by demographic, clinical, awareness, and attitudinal factors among high-risk women $(n=962)$

\begin{tabular}{|c|c|c|c|c|}
\hline & $\begin{array}{c}\text { Total } \\
(n=962)\end{array}$ & $\begin{array}{l}\text { Yes, would consider } \\
\quad(n=318)\end{array}$ & $\begin{array}{l}\text { Don't know } \\
(n=277)\end{array}$ & $\begin{array}{l}\text { No, would not consider } \\
\qquad(n=367)\end{array}$ \\
\hline \multicolumn{5}{|l|}{ Demographic characteristics } \\
\hline \multicolumn{5}{|l|}{ Race/ethnicity } \\
\hline White/non-Hispanic & $901(93.7)$ & $295(92.8)$ & $264(95.3)$ & $342(93.2)$ \\
\hline Other & $61(6.3)$ & $23(7.2)$ & $13(4.7)$ & $25(6.8)$ \\
\hline \multicolumn{5}{|l|}{ Marital status } \\
\hline Married & $722(75.1)$ & $234(73.6)$ & $200(72.2)$ & $288(78.5)$ \\
\hline Other & $240(25.0)$ & $84(26.4)$ & $77(27.8)$ & $79(21.5)$ \\
\hline \multicolumn{5}{|l|}{ Education } \\
\hline$<$ High school & $69(7.2)$ & $23(7.2)$ & $17(6.1)$ & $29(7.9)$ \\
\hline Completed high school & $207(21.5)$ & $61(19.2)$ & $61(22.0)$ & $85(23.2)$ \\
\hline College and beyond & $686(71.3)$ & $234(73.6)$ & $199(71.8)$ & $253(68.9)$ \\
\hline \multicolumn{5}{|l|}{ Age (yr) } \\
\hline$<41$ & $650(67.6)$ & $216(67.9)$ & $182(65.7)$ & $252(68.7)$ \\
\hline$>41$ & $312(32.4)$ & $102(32.1)$ & $95(34.3)$ & $115(31.3)$ \\
\hline \multicolumn{5}{|l|}{ Religion $^{a}$} \\
\hline Catholic & $271(28.2)$ & $73(23.0)$ & $72(26.0)$ & $126(34.3)$ \\
\hline Christian/Protestant & $343(35.7)$ & $110(34.6)$ & $94(33.9)$ & 139 (37.9) \\
\hline Jewish & $169(17.6)$ & $68(21.4)$ & $60(21.7)$ & $41(11.2)$ \\
\hline Other & 179 (18.6) & $67(21.1)$ & $51(18.4)$ & $61(16.6)$ \\
\hline \multicolumn{5}{|l|}{ Currently have children } \\
\hline Yes & $723(75.2)$ & $232(73.0)$ & $204(73.7)$ & $287(78.2)$ \\
\hline No & $239(24.8)$ & $86(27.0)$ & $73(26.4)$ & $80(21.8)$ \\
\hline \multicolumn{5}{|l|}{ Wish to have more children ${ }^{a}$} \\
\hline Yes & $132(13.7)$ & $52(16.4)$ & $45(16.3)$ & $35(9.5)$ \\
\hline No & $779(81.0)$ & $254(79.9)$ & $213(76.9)$ & $312(85.0)$ \\
\hline Don't know & $51(5.3)$ & $12(3.8)$ & $19(6.9)$ & $20(5.5)$ \\
\hline \multicolumn{5}{|l|}{ Medical characteristics } \\
\hline \multicolumn{5}{|c|}{ Personal history of breast cancer } \\
\hline Yes, before age of $50 \mathrm{yr}$ & $91(9.46)$ & $38(11.95)$ & $25(9.03)$ & $28(7.63)$ \\
\hline Yes, after age of $50 \mathrm{yr}$ & $288(29.94)$ & $78(24.53)$ & $89(32.13)$ & $121(32.97)$ \\
\hline No & $583(60.60)$ & $202(63.52)$ & $163(58.84)$ & $218(59.40)$ \\
\hline \multicolumn{5}{|c|}{ Personal history of ovarian cancer } \\
\hline Yes & $168(17.5)$ & $55(17.3)$ & $42(15.2)$ & $71(19.4)$ \\
\hline No & $794(82.5)$ & $263(82.7)$ & $235(84.8)$ & $296(80.7)$ \\
\hline \multicolumn{5}{|c|}{ FDR has breast or ovarian cancer } \\
\hline Yes & $601(62.5)$ & $194(61.0)$ & $179(64.6)$ & $228(62.1)$ \\
\hline \multirow[t]{2}{*}{ No } & $361(37.5)$ & $124(39.0)$ & $98(35.4)$ & $139(37.9)$ \\
\hline & & & & (Continued) \\
\hline
\end{tabular}


Table 1 Continued

\begin{tabular}{|c|c|c|c|c|}
\hline & $\begin{array}{c}\text { Total } \\
(n=962)\end{array}$ & $\begin{array}{l}\text { Yes, would consider } \\
\quad(n=318)\end{array}$ & $\begin{array}{l}\text { Don’t know } \\
(n=277)\end{array}$ & $\begin{array}{l}\text { No, would not consider } \\
\quad(n=367)\end{array}$ \\
\hline \multicolumn{5}{|l|}{ Personal $B R C A$ mutation } \\
\hline Yes & $471(49.0)$ & $140(44.0)$ & $143(51.6)$ & $188(51.2)$ \\
\hline No & $334(34.7)$ & $124(39.0)$ & $90(32.5)$ & $120(32.7)$ \\
\hline Variant & $125(13.0)$ & $43(13.5)$ & $35(12.6)$ & $47(12.8)$ \\
\hline Other (Don't know and prefer not to answer) & $32(3.3)$ & $11(3.5)$ & $9(3.3)$ & $12(3.3)$ \\
\hline \multicolumn{5}{|l|}{ Female family member with $B R C A$ mutation } \\
\hline Yes & $383(39.8)$ & $120(37.7)$ & $115(41.5)$ & $148(40.3)$ \\
\hline No & $318(33.1)$ & $102(32.1)$ & $86(31.1)$ & $130(35.4)$ \\
\hline Variant & $261(27.1)$ & $96(30.2)$ & $76(27.4)$ & $89(24.3)$ \\
\hline \multicolumn{5}{|l|}{ Prenatal genetic test ${ }^{a}$} \\
\hline Yes & $124(12.9)$ & $61(19.2)$ & $29(10.5)$ & $34(9.3)$ \\
\hline No & $639(66.4)$ & $194(61.0)$ & $177(63.9)$ & $268(73.0)$ \\
\hline Other (Don't know and never pregnant) & $199(20.7)$ & $63(19.8)$ & $71(25.6)$ & 65 (17.7) \\
\hline \multicolumn{5}{|l|}{ Ever used in vitro fertilization } \\
\hline Yes & $25(2.6)$ & $10(3.1)$ & $10(3.6)$ & $5(1.4)$ \\
\hline No & $937(97.4)$ & $308(96.9)$ & $267(96.4)$ & $362(98.6)$ \\
\hline \multicolumn{5}{|l|}{ Awareness } \\
\hline \multicolumn{5}{|l|}{ Heard of PGD before survey ${ }^{a}$} \\
\hline Yes & $196(20.4)$ & $92(28.9)$ & $53(19.1)$ & $51(13.9)$ \\
\hline No & $766(79.6)$ & $226(71.1)$ & $224(80.9)$ & $316(86.1)$ \\
\hline \multicolumn{5}{|l|}{ Attitudes } \\
\hline \multicolumn{5}{|l|}{$\begin{array}{l}\text { PGD acceptable for individuals at risk } \\
\text { for } \mathrm{HBOC}^{a}\end{array}$} \\
\hline Yes & $512(53.2)$ & $281(88.4)$ & $123(44.4)$ & $108(29.4)$ \\
\hline No & $159(16.5)$ & $8(2.5)$ & $18(6.5)$ & $133(36.2)$ \\
\hline Not sure & $291(30.3)$ & $29(9.1)$ & $136(49.1)$ & $126(34.3)$ \\
\hline \multicolumn{5}{|l|}{$\begin{array}{l}\text { Women at increased risk for HBOC may } \\
\text { choose not to have children due to fear } \\
\text { of passing on a hereditary cancer gene }\end{array}$} \\
\hline Yes & $572(59.5)$ & $227(71.4)$ & $160(57.8)$ & $185(50.4)$ \\
\hline No & $150(15.6)$ & $35(11.0)$ & $33(11.9)$ & $82(22.3)$ \\
\hline Not sure & $240(25.0)$ & $56(17.6)$ & $84(30.3)$ & $100(27.3)$ \\
\hline \multicolumn{5}{|l|}{$\begin{array}{l}\text { Provided information about PGD to } \\
\text { individuals at risk for } \mathrm{HBOC}^{a}\end{array}$} \\
\hline Yes & 743 (77.2) & 313 (98.4) & $220(79.4)$ & $210(57.2)$ \\
\hline No & $77(8.0)$ & $2(0.6)$ & $6(2.2)$ & 69 (18.8) \\
\hline Not sure & $142(14.8)$ & $3(0.9)$ & $51(18.4)$ & $88(24.0)$ \\
\hline & & & & (Continued) \\
\hline
\end{tabular}




\section{Table 1 Continued}

\begin{tabular}{|c|c|c|c|c|}
\hline & $\begin{array}{c}\text { Total } \\
(n=962)\end{array}$ & $\begin{array}{l}\text { Yes, would consider } \\
\quad(n=318)\end{array}$ & $\begin{array}{l}\text { Don't know } \\
(n=277)\end{array}$ & $\begin{array}{l}\text { No, would not consider } \\
\qquad(n=367)\end{array}$ \\
\hline \multicolumn{5}{|l|}{ Concerns about $\mathrm{PGD}^{a}$} \\
\hline Too much like playing God & $203(21.1)$ & $10(3.1)$ & $60(21.7)$ & $133(36.2)$ \\
\hline Too new to be used safely & $68(7.1)$ & $24(7.6)$ & $20(7.2)$ & $24(6.5)$ \\
\hline Not affordable & $230(23.9)$ & $150(47.2)$ & $41(14.8)$ & $39(10.6)$ \\
\hline Can be used for the wrong purpose & $277(28.8)$ & $80(25.2)$ & $89(32.1)$ & $108(29.4)$ \\
\hline Other & $184(19.1)$ & $54(17.0)$ & $67(24.2)$ & $63(17.2)$ \\
\hline \multicolumn{5}{|l|}{ Benefits of PGD ${ }^{a}$} \\
\hline $\begin{array}{l}\text { Parents can ensure babies without } \\
\text { mutations }\end{array}$ & $410(42.6)$ & $181(56.9)$ & $116(41.9)$ & $113(30.8)$ \\
\hline $\begin{array}{l}\text { Parents can increase chances their } \\
\text { child will have the features they } \\
\text { want }\end{array}$ & $7(0.7)$ & $0(0.0)$ & $3(1.1)$ & $4(1.1)$ \\
\hline Cost of healthcare will be less & $13(1.4)$ & $2(0.6)$ & $7(2.5)$ & $4(1.1)$ \\
\hline $\begin{array}{l}\text { Certain genetic disease will be } \\
\text { wiped out forever }\end{array}$ & $253(26.3)$ & $107(33.7)$ & $76(27.4)$ & $70(19.1)$ \\
\hline Other & $279(29.0)$ & $28(8.8)$ & $75(27.1)$ & $176(48.0)$ \\
\hline \multicolumn{5}{|l|}{ How PGD is considered ${ }^{a}$} \\
\hline Mainly health and safety & $481(50.0)$ & $259(81.5)$ & $122(44.0)$ & $100(27.3)$ \\
\hline Mainly religion and morality & $121(12.6)$ & $4(1.3)$ & $18(6.5)$ & 99 (27.) \\
\hline $\begin{array}{l}\text { Both health and safety and religion } \\
\text { and morality }\end{array}$ & $308(32.0)$ & $50(15.7)$ & $118(42.6)$ & $140(38.2)$ \\
\hline Other & $52(5.4)$ & $5(1.6)$ & $19(6.7)$ & $28(7.6)$ \\
\hline
\end{tabular}

ability of PGD, most women in this study were likely considering these issues with respect to amniocentesis or CVS. Thus, this group may view PGD as a lower risk option and possibly more in line with their personal, religious, or moral beliefs.

Another factor associated with acceptance was having previously heard of PGD. Almost $80 \%$ of our sample had not previously heard of PGD. These rates of awareness are similar to both the general population and the high-risk groups of women. ${ }^{10,19}$ Given that so few women had heard of PGD before the survey, their responses to the question of PGD acceptability may have been influenced by the definition provided in the survey. In the study of $B R C A$ mutation carriers' attitudes toward PGD conducted in the United Kingdom, ${ }^{18}$ respondents were given an option to provide additional comments related to PGD for $B R C A$ mutations. Because this survey was conducted in the year during which the UK Human Fertilization and Embryology Authority was eliciting patient views related to PGD for $B R C A$, very few women were likely to have previously heard of PGD. However, in this study, women were provided a brochure related to PGD including information about the process, advantages/disadvantages or PGD, and alternative forms of prenatal diagnosis that they were asked to review before completing the study questionnaire. Thus, this design had a unique advantage of providing more in depth information about a largely previously unknown technology. Therefore, these responses likely reflect individuals' "initial" reaction to PGD and may provide some insight into explanations for lower levels of acceptance among individuals who had not previously heard of PGD. The most commonly expressed attitudes related to PGD included that: (1) there are preventive options for those with a $B R C A$ mutation; (2) individuals can have a good quality of life even with a cancer diagnosis; and (3) their own children who they love and cherish may not have been born had PGD been available. ${ }^{18}$

Although previous studies show that high-risk women have previously been in favor of offering PGD to others, ${ }^{10,18}$ none have examined whether this attitude varied based on personal acceptance of PGD. In this study, women who did not consider it acceptable for others to have PGD were less likely to accept PGD for themselves. These individuals may represent the group that is opposed to PGD for ethical reasons. There are several ethical considerations related to the use of PGD for $B R C A$. For example, some argue that adult onset conditions with incomplete penetrance (e.g., HBOC associated with $B R C A$ mutations) are not as "serious" as those with almost complete penetrance affecting infants or children. ${ }^{22}$ Some have also raised concerns about the ethics of PGD for adult onset diseases such as breast cancer, where an argument cannot be made that the procedure prevents painful disability or death in early life. ${ }^{23}$ Some may be concerned that using PGD for adult onset conditions will lead to a slippery slope resulting in use of this technology for nonmedical indications (e.g., sex selection or selection of physical features such as height). ${ }^{19}$ There is a long-standing debate about 
Table 2 Logistic regression model of predictors of acceptance of preimplantation genetic diagnosis (PGD) among high-risk women $(n=681)$

\begin{tabular}{|c|c|}
\hline & $\begin{array}{l}\text { Odds ratio }(95 \% \\
\text { confidence interval) }\end{array}$ \\
\hline \multicolumn{2}{|l|}{ Demographic characteristics } \\
\hline \multicolumn{2}{|l|}{ Religion } \\
\hline Other & 1.00 \\
\hline Catholic & $0.61(0.31-1.19)$ \\
\hline Christian/Protestant & $0.86(0.45-1.65)$ \\
\hline Jewish & $0.77(0.37-1.59)$ \\
\hline \multicolumn{2}{|l|}{ Wish to have more children } \\
\hline Yes & 1.00 \\
\hline $\mathrm{No}^{a}$ & $0.17(0.07-0.38)$ \\
\hline \multicolumn{2}{|l|}{ Medical characteristics } \\
\hline \multicolumn{2}{|l|}{ Personal history of breast cancer } \\
\hline No & 1.00 \\
\hline Yes, before age of $50 \mathrm{yr}$ & $1.43(0.67-3.05)$ \\
\hline Yes, after age of $50 \mathrm{yr}$ & $0.72(0.43-1.19)$ \\
\hline \multicolumn{2}{|l|}{ Prenatal genetic test } \\
\hline Other (Don't know and never pregnant) & 1.00 \\
\hline Yes $^{a}$ & $2.45(1.09-5.51)$ \\
\hline No & $1.06(0.57-1.95)$ \\
\hline \multicolumn{2}{|l|}{ Awareness } \\
\hline \multicolumn{2}{|l|}{ Heard of PGD before survey } \\
\hline Yes & 1.00 \\
\hline $\mathrm{No}^{a}$ & $0.51(0.29-0.90)$ \\
\hline \multicolumn{2}{|l|}{ Attitudes } \\
\hline \multicolumn{2}{|l|}{$\begin{array}{l}\text { PGD acceptable for individuals at risk for } \\
\text { HBOC }\end{array}$} \\
\hline Yes & 1.00 \\
\hline $\mathrm{No}^{a}$ & $0.29(0.10-0.81)$ \\
\hline Not sure ${ }^{a}$ & $0.43(0.24-0.79)$ \\
\hline \multicolumn{2}{|l|}{$\begin{array}{l}\text { PGD information for individuals at risk for } \\
\text { HBOC }\end{array}$} \\
\hline Yes & 1.00 \\
\hline No & $0.19(0.03-1.19)$ \\
\hline Not sure ${ }^{a}$ & $0.16(0.04-0.57)$ \\
\hline \multicolumn{2}{|l|}{$\begin{array}{l}\text { Women at increased risk for HBOC may } \\
\text { choose not to have children due to fear } \\
\text { of passing on a hereditary cancer gene }\end{array}$} \\
\hline Yes & 1.00 \\
\hline No & $0.84(0.42-1.68)$ \\
\hline Not sure & $0.73(0.41-1.29)$ \\
\hline
\end{tabular}

Odds ratio $(95 \%$

confidence interval)

Concerns about PGD

Too much like playing God

1.00

Too new to be used safely ${ }^{a}$

Not affordable ${ }^{a}$

$11.07(4.26-28.77)$

Can be used for the wrong purpose $^{a}$

$5.59(2.25-13.90)$

Benefits of PGD

Other

Parents can ensure babies without mutations ${ }^{a}$

Cost of healthcare will be less

Certain genetic disease will be wiped out forever ${ }^{a}$

How PGD is considered

Mainly health and safety

Mainly religion and morality ${ }^{a}$

$0.14(0.04-0.48)$

Both health and safety and religion and morality ${ }^{a}$

$0.31(0.18-0.53)$

Other $^{a}$

$0.19(0.05-0.67)$

the ethics of using PGD centered on individual beliefs about when life begins and the associated issues surrounding pregnancy termination. Limited research exists on high-risk populations' attitudes and expectations regarding whether embryos created through IVF, but not used, constitutes abortion. Cameron and Williamson ${ }^{24}$ examined the issue from a bio-ethics perspective and concluded that PGD couples tended to view implantation of an unaffected embryo as a more ethically acceptable choice than prenatal diagnosis followed by abortion. They further suggest women bond with implanted embryos as they develop in utero and may not give the same consideration to those retained in the laboratory. They conclude that the public sees abortion of a fetus as "killing," whereas in PGD, unused embryos are "allowed to die." 24

Those individuals who viewed PGD more in the context of religion as opposed to factors such as affordability, cost, safety, and health were less likely to accept PGD. Little research has been conducted regarding patient religion and use of PGD; however, the topic has been explored in the context of prenatal diagnosis. A recent study of Pakistani women in the United Kingdom concluded women's attitudes toward prenatal diagnosis and termination of pregnancy were influenced by various factors and not primarily religion. ${ }^{25}$ Other studies of Israeli populations outside the United States indicate that strong religious beliefs are the primary reason for low use of prenatal diagnostic testing. ${ }^{26-28}$ Conversely, in a similar survey among primarily Catholic women in Mexico indicates that $71 \%$ of the sample of 264 women indicated they would terminate a pregnancy if an anomaly were found. ${ }^{29}$ In another study of 77 Spanish individuals attending genetic counseling for hereditary breast ovarian cancer, there was no association between individuals who considered themselves to be religious and favor- 
able attitudes toward PGD. ${ }^{9}$ For women living in the United States, results among Hispanic, primarily Catholic women were vastly different. In a study examining acceptance of alphafetoprotein testing among pregnant women in California, Spanishspeaking Latinas, and women scoring high on a religiosity scale were least likely women to accept the test. ${ }^{30}$ Thus, the role of religion in acceptance of testing which may result in need for decision making about pregnancy termination is varied across culture, religions, and country of residence.

To our knowledge, this is the largest study of PGD acceptance among women in the United States who are concerned about HBOC. It is also the first to examine predictors of PGD acceptance in women concerned about HBOC. However, our results must be considered in light of certain limitations. First, the vast majority $(80 \%)$ had not heard about PGD before the study. Similar to previous studies related to PGD among highrisk women, ${ }^{6,9,10}$ our participants were given a brief definition of PGD. Because of this approach, we cannot determine whether women understood the complexities related to PGD including the process of IVF (e.g., hormonal treatment, ovum stimulation, a limited success rate, and high cost). As suggested in the conclusion of another study assessing attitudes toward PGD among high-risk women and healthcare providers, ${ }^{9}$ it is possible that their attitudes may have been different had additional details related to the complexities of PGD been provided. However, given the recent Direct-to-Consumer marketing of genetic technologies, including PGD, ${ }^{31}$ it is possible that women may receive an even more simplified message from genetic testing companies. Our results may provide some insight into the population's initial reactions to this technology and identify some of the affective attitudes that high-risk individuals may "present" with when seeking consultation for or being presented information by a healthcare provider related to PGD. Given recent evidence to suggest that women are actively seeking PGD for $B R C A$, it becomes even more important to better understand these issues. ${ }^{15-17}$ Thus, these findings may give some insight for providers about the baseline knowledge/ attitudes among high-risk women related to PGD that may inform both counseling and educational strategies.

Respondents to our survey were based on a convenience sample of individuals who were likely seeking information about HBOC on the website of an advocacy organization; thus, this group may represent a highly motivated group of individuals. However, a common criticism of research among women with HBOC is that much of the psychosocial research has been published from a few investigators using high-risk cohorts or kindreds. Thus, in some ways, our study may more likely include women who do not receive care at academic centers that specialize in HBOC. Second, the population was a homogenous sample comprised primarily of white, married college graduates. Because mutations have been identified in a broad array of racial/ethnic groups from a variety of SES backgrounds, it is not possible to generalize the results of this study to describe the entire population of high-risk women. However, this study contains more representation from groups of particular interest (e.g., $B R C A$ mutation carriers, those who wish to have more children), when compared with previous studies of this group. $6,10,18$ Finally, in addition, the cross-sectional nature of the study limits the ability to make causal inferences about the relationship between the factors assessed and their relationship to acceptance.

\section{CONCLUSIONS}

Debates surrounding the use of PGD for $B R C A$ are likely to continue into the foreseeable future. However, women at in- creased risk for hereditary cancer are considering PGD as part of their reproductive decision making are making decisions today. ${ }^{16}$ Thus, it is important to better understand existing levels of awareness and attitudes toward this technology to provide optimal counseling and support for high-risk women. The struggles of this group are eloquently summarized in a passage from the book "Pretty is What Changes" 20 by Jessica Queller, a young unmarried woman who tested positive for a $B R C A$ mutation nearing the age of 35 years and considering prophylactic oophorectomy.

"As I've learned, the advances of biotechnology offer an array of choices, but they also come with ethical dilemmas. I've decided to purchase sperm and be artificially inseminated, but I can take it a step further. A technique called preimplantation genetic diagnosis, or PGD, would enable me to create embryos in Petri dishes and genetically test them for the $B R C A$ mutation. I could choose to implant only the embryos that do not carry the mutation. I believe in utilizing biotechnology to promote health. Of course, I don't want my children to inherit the breast cancer gene, but there is no existing method to alter the genetics of an embryo. The only option is to select the embryos that do not carry the faulty gene. Had this technology been available in 1969, I would have ended up in the trash can. Can I, in good faith, choose embryos that don't have the mutation and destroy others? Is taking action to ensure my unborn child will not have to go through the terrors my mother, sister, and I have suffered the responsible choice? Or is it immoral to extinguish a life merely because it carries a gene that I myself live with?” (p. 239).

\section{ACKNOWLEDGMENTS}

This research was supported by a Grant from the American Cancer Society (RSGPB07-019-01-CPPB).

\section{REFERENCES}

1. Carter RF. BRCA1, BRCA2 and breast cancer: a concise clinical review. Clin Invest Med 2001:24:147-157.

2. Miki Y, Swensen J, Shattuck-Eidens D, et al. A strong candidate for the breast and ovarian cancer susceptibility gene BRCA1. Science 1994:266:66-71.

3. Wooster R, Bignell G, Lancaster J, et al. Identification of the breast cancer susceptibility gene BRCA2. Nature 1995;378:789-792.

4. Brose MS, Rebbeck TR, Calzone KA, Stopfer JE, Nathanson KL, Weber BL. Cancer risk estimates for BRCA1 mutation carriers identified in a risk evaluation program. J Natl Cancer Inst 2002;94:1365-1372.

5. King MC, Marks JH, Mandell JB. Breast and ovarian cancer risks due to inherited mutations in BRCA1 and BRCA2. Science 2003;302:643-646.

6. Staton AD, Kurian AW, Cobb K, Mills MA, Ford JM. Cancer risk reduction and reproductive concerns in female BRCA1/2 mutation carriers. Fam Cancer 2008;7:179-186.

7. Friedman LC, Kramer RM. Reproductive issues for women with BRCA mutations. J Natl Cancer Inst Monogr 2005;(34):83-86.

8. Smith KR, Ellington L, Chan AY, Croyle RT, Botkin JR. Fertility intentions following testing for a BRCA1 gene mutation. Cancer Epidemiol Biomarkers Prev 2004;13:733-740.

9. Fortuny D, Balmana J, Grana B, et al. Opinion about reproductive decision making among individuals undergoing BRCA1/2 genetic testing in a multicentre Spanish cohort. Hum Reprod 2009;24:1000-1006.

10. Quinn G, Vadaparampil S, Wilson C, et al. Attitudes of high-risk women toward preimplantation genetic diagnosis. Fertil Steril 2009;91:2361-2368.

11. Cunniff C. Prenatal screening and diagnosis for pediatricians. Pediatrics 2004; $114: 889-894$

12. Rappaport VJ. Prenatal diagnosis and genetic screening-integration into prenatal care. Obstet Gynecol Clin North Am 2008;35:435-458.

13. Baruch S, Kaufman D, Hudson KL. Genetic testing of embryos: practices and perspectives of US in vitro fertilization clinics. Fertil Steril 2008;89:1053-1058.

14. Ogilvie CM, Braude PR, Scriven PN. Preimplantation genetic diagnosis - an overview. J Histochem Cytochem 2005;53:255-260.

15. Jasper MJ, Liebelt J, Hussey ND. Preimplantation genetic diagnosis for BRCA1 exon 13 duplication mutation using linked polymorphic markers resulting in a live birth. Prenat Diagn 2008;28:292-298.

16. Sagi M, Weinberg N, Eilat A, et al. Preimplantation genetic diagnosis for BRCA1/2-a novel clinical experience. Prenat Diagn 2009;29:508-513.

17. Offit $\mathrm{K}$, Kohut K, Clagett $\mathrm{B}$, et al. Cancer genetic testing and assisted reproduction. J Clin Oncol 2006;24:4775-4782. 
18. Menon U, Harper J, Sharma A, et al. Views of BRCA gene mutation carriers on preimplantation genetic diagnosis as a reproductive option for hereditary breast and ovarian cancer. Hum Reprod 2007;22:1573-1577.

19. Hudson KL. Preimplantation genetic diagnosis: public policy and public attitudes. Fertil Steril 2006;85:1638-1645.

20. Queller J. Pretty is what changes. New York: Spiegel and Grau, 2008.

21. Paek B, Goldberg JD, Albanese CT. Prenatal diagnosis. World J Surg 2003; 27:27-37.

22. Niermeijer MF, de Wert G, Dondorp W. Preimplantation genetic diagnosis for cancer. Lancet Oncol 2006;7:794-795.

23. Testart J, Sele B. Towards an efficient medical eugenics: is the desirable always the feasible? Hum Reprod 1995;10:3086-3090.

24. Cameron $\mathrm{C}$, Williamson $\mathrm{R}$. Is there an ethical difference between preimplantation genetic diagnosis and abortion? J Med Ethics 2003;29:90-92.

25. Ahmed S, Hewison J, Green JM, Cuckle HS, Hirst J, Thornton JG. Decisions about testing and termination of pregnancy for different fetal conditions: a qualitative study of European White and Pakistani mothers of affected children. J Genet Couns 2008;17:560-572.
26. Jaber L, Dolfin T, Shohat T, Halpern GJ, Reish O, Fejgin M. Prenatal diagnosis for detecting congenital malformations: acceptance among Israeli Arab women. Isr Med Assoc J 2000;2:346-350.

27. Sheiner E, Shoham-Vardi I, Weitzman D, Gohar J, Carmi R. Decisions regarding pregnancy termination among Bedouin couples referred to third level ultrasound clinic. Eur J Obstet Gynecol Reprod Biol 1998;76:141-146.

28. Shohat M, Frimer H, Shohat-Levy V, et al. Prenatal diagnosis of Down syndrome: ten year experience in the Israeli population. Am J Med Genet A 2003;122A:215-222.

29. Mayen-Molina DG, Hernandez-Gonzalez C, Grether-Gonzalez P. [Attitude to and acceptance of prenatal cytogenetic diagnosis by pregnant women]. Ginecol Obstet Mex 1997;65:107-110.

30. Press N, Browner $\mathrm{CH}$. Characteristics of women who refuse an offer of prenatal diagnosis: data from the California maternal serum alpha fetoprotein blood test experience. Am J Med Genet 1998;78:433-445.

31. Geransar R, Einsiedel E. Evaluating online direct-to-consumer marketing of genetic tests: informed choices or buyers beware? Genet Test 2008;12:13-23.

\section{Erratum}

ACMG practice guideline: Genetic evaluation of short stature: Erratum

In the article that appeared on page 465 of volume 11, number 6, Figure 1 was incorrect. The correct figure appears below.

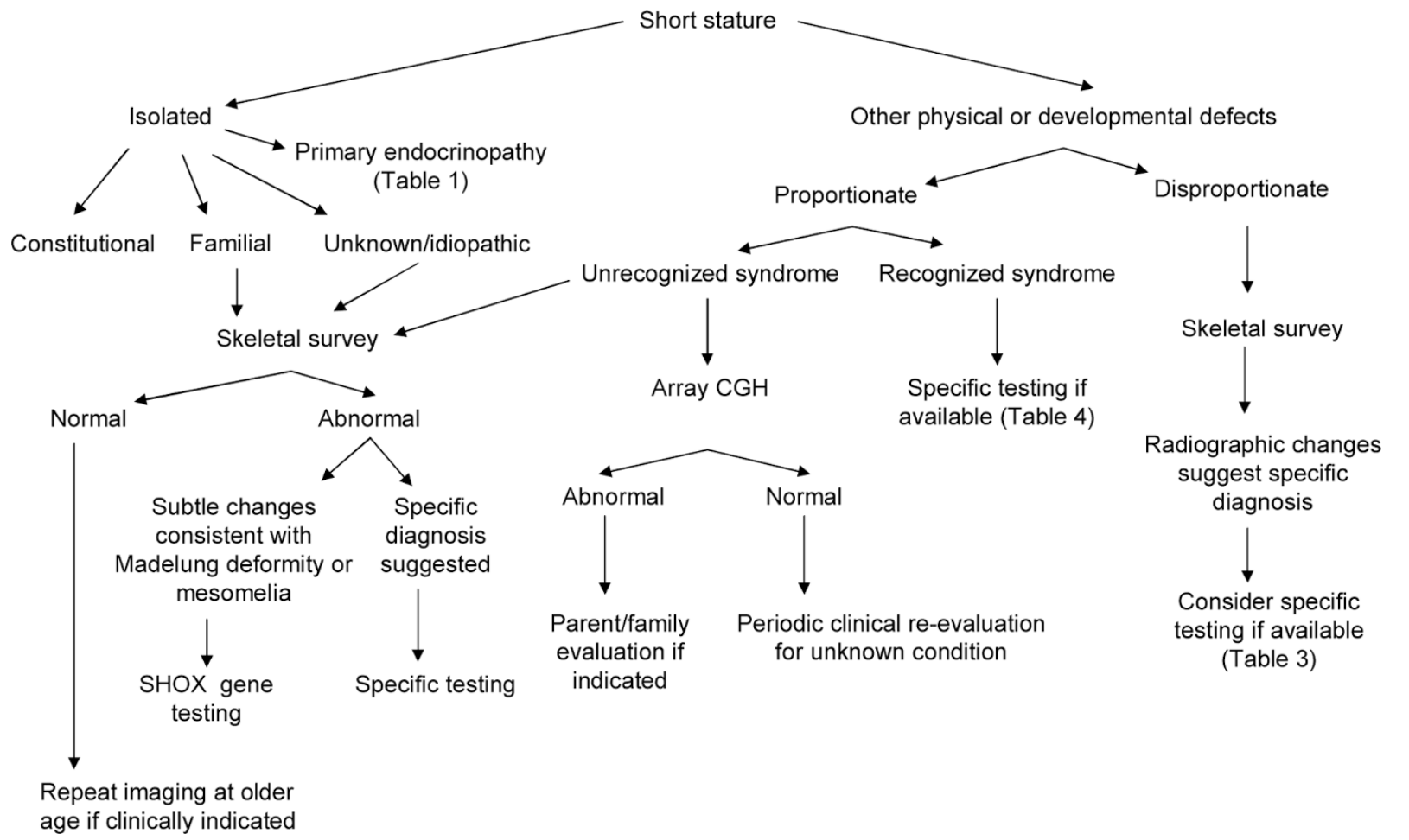

\section{REFERENCE}

Seaver LF, Irons M on behalf of the American College of Medical Genetics (ACMG) Professional Practice and Guidelines Committee. ACMG practice guideline: Genetic evaluation of short stature. Genet Med 2009;11:465-470. 